Check for updates

Cite this: RSC Adv., 2017, 7, 18162

Received 15th February 2017

Accepted 15th March 2017

DOI: 10.1039/c7ra01904a

rsc.li/rsc-advances

\section{Non-contact $\mathrm{Mn}_{1-x} \mathrm{Ni}_{x} \mathrm{Fe}_{2} \mathrm{O}_{4}$ ferrite nano-heaters for biological applications - heat energy generated by NIR irradiation}

\author{
Robert Pązik, (D) *ab Emilia Zachanowicz, ${ }^{c}$ Błażej Pożniak, ${ }^{d}$ Małgorzata Małecka, ${ }^{a}$ \\ Aleksander Zięcina a and Łukasz Marciniak iD a
}

\begin{abstract}
$\mathrm{Mn}_{1-x} \mathrm{Ni}_{x} \mathrm{Fe}_{2} \mathrm{O}_{4}$ nanoparticles with primary particle size of $6 \mathrm{~nm} \pm 4 \mathrm{~nm}$ were synthesized using fast and effective microwave stimulated technique without addition of surfactants or other specific agents to open more flexible post-surface modification potential. Structural, chemical and morphological characterization were performed using XRD, SEM-EDS and TEM techniques. DLS and absorption measurements were performed in order to evaluate hydrodynamic size of particles/objects and nanoparticles dispersion stability upon addition of stabilizing agents in water. The J774.E murine macrophage and U2OS human osteosarcoma cells exposed to particle dispersions revealed high loading of macrophages and moderate loading of osteosarcoma cells. Difference was ascribed to phagocytic activity of macrophages and their explicit role in elimination of particulate matter under in vivo conditions. It was shown that the effective heat generation can be achieved with $\mathrm{Mn}_{1-x} \mathrm{Ni}_{x} \mathrm{Fe}_{2} \mathrm{O}_{4}$ magnetic ferrites by using NIR light irradiation instead of AC magnetic field reaching temperatures suitable for application in hyperthermia-based therapies.
\end{abstract}

\section{Introduction}

For more than thirty years ferrite nanoparticles have attracted considerable attention due to their outstanding magnetic properties and high prospect in biomedical applications such as magnetic drug delivery, magnetic resonance imaging, magnetic separation or hyperthermia. ${ }^{1-5}$ There are thousands of publications devoted to the most representative and incredibly popular $\mathrm{Fe}_{3} \mathrm{O}_{4}$ nanoparticles. On the other hand, rather less efforts are directed towards the $\mathrm{MnFe}_{2} \mathrm{O}_{4}$ nanoparticles substituted with $\mathrm{Ni}^{2+}$ ions. However number of articles is constantly increasing due to fact that $\mathrm{MnFe}_{2} \mathrm{O}_{4}$ is more chemically stable (lack of Fenton reaction leading to cytotoxicity) and has better or comparable magnetic properties. ${ }^{6-10}$ What makes these materials interesting is that the $\mathrm{MnFe}_{2} \mathrm{O}_{4}$ is a typical normal spinel whereas $\mathrm{NiFe}_{2} \mathrm{O}_{4}$ shows relatively high cationic disorder (inverted spinel). In fact, substitution of $\mathrm{Mn}^{2+}$ with $\mathrm{Ni}^{2+}$ leads to the compositional and structural dependent magnetic properties like for instance in the case of $\mathrm{Co}_{1-x} \mathrm{Mn}_{x} \mathrm{Fe}_{2} \mathrm{O}_{4}$ ferrites. ${ }^{11,12}$

\footnotetext{
Institute of Low Temperature and Structure Research, PAS, Okólna 2, 50-422 Wrocław, Poland. E-mail: R.Pazik@int.pan.wroc.pl; Web: http://www.int.pan.wroc. pl; Fax: +48-71-344-10-29; Tel: +48-71-3954-190

${ }^{b}$ Medicinal Chemistry Department, Institute of Biotechnology, University of Rzeszow, Pigonia 1, 35-959 Rzeszow, Poland

'Polymer Engineering and Technology Division, Wroclaw University of Technology, 50370 Wroctaw, Poland

${ }^{d}$ Department of Pharmacology and Toxicology, Faculty of Veterinary Medicine, Wrocław University of Environmental and Life Sciences, Ul. Norwida 25, 50-375 Wroctaw, Poland
}

Development of new non-contact nano-heaters, especially for the heat-triggered drug release or hyperthermia, is of great importance especially for theranostics. However, several challenges were identified like proper control over particle size distribution, morphology, surface modification, biocompatibility, stability in biological media, controlling target temperature, safe dosage and other factors. ${ }^{13}$ Usually heating of magnetic nanoparticles is realized by taking advantage of their magnetic properties. By using alternating magnetic field nanoparticles heat inductively due to the magnetic and residual losses (Neel, Brownian relaxations) upon magnetization-demagnetization cycles. ${ }^{4}$ In one study, it was shown that in order to destroy completely cancer tumor the action of elevated temperature (42$50{ }^{\circ} \mathrm{C}$ ) must be sustained for minimum 30 minutes. ${ }^{14}$

Alternative way of heat energy generation, in the nanoparticle systems, relies on non-contact, direct sample irradiation with light using different wavelengths within the so called biological optical window (650-1350 nm) being harmless for the illuminated tissues. ${ }^{\mathbf{1 5 - 1 7}}$ Moreover, the effect of light to heat conversion might be used not only for ablation of tumors but also, materials showing this functionality might act as agents for heat triggered drug delivery as well. ${ }^{18}$ Last four years brought into the light several scientific reports showing huge prospects of utilizing magnetic iron oxide nanoparticles for photothermal therapies ${ }^{\mathbf{1 9 - 2 4}}$ by stimulation with NIR irradiation as well as Espinosa et al. proposed to take advantage out of synergistic effect of both magnetic and NIR light to heat conversion realized simultaneously. ${ }^{21}$ Except idea of using magnetic nanoparticles it was shown that the same effect can be achieved on 
multi walled carbon nanotubes in the first (650-950 nm) and second $(1000-1350 \mathrm{~nm})$ biological windows ${ }^{25}$ as well as metallic nanoparticles or quantum dots. ${ }^{17,26}$

In this paper, we report on attractive possibility of heat energy generation in $\mathrm{Mn}_{1-x} \mathrm{Ni}_{x} \mathrm{Fe}_{2} \mathrm{O}_{4}$ by direct NIR irradiation performed on dry nanopowders and their dispersions without using alternating magnetic field. In our previous studies we have observed the chemical transformation of the $\mathrm{Fe}_{3} \mathrm{O}_{4}$ into $\alpha$ $\mathrm{Fe}_{2} \mathrm{O}_{3}$ and strong temperature effects during micro-Raman measurements when $\mathrm{MFe}_{2} \mathrm{O}_{4}$ nanoparticles were exposed to the NIR irradiation..$^{27}$ Already, several very interesting papers devoted to the $\mathrm{MnFe}_{2} \mathrm{O}_{4}$ nanoferrites for application in hyperthermia induced by AC magnetic field can be found..$^{13,28,29}$ However, there is no single scientific report on inducing heat energy in $\mathrm{Ni}^{2+}$ substituted nanoparticles of the $\mathrm{Mn}_{1-x} \mathrm{Ni}_{x} \mathrm{Fe}_{2} \mathrm{O}_{4}$ using NIR irradiation. Since the dispersions of nanoparticles were prepared in water, the $808 \mathrm{~nm}$ diode was used as the excitation source (instead of $975 \mathrm{~nm}$ ). Comparing to the latter wavelength (commonly used in nanoparticles co-doped with lanthanides ions like $\mathrm{Yb}^{3+}-\mathrm{Er}^{3+}$ ) the $808 \mathrm{~nm}$ is 25 times less absorbed by water. Therefore, possibility of overheating the healthy cells exposed to this wavelength is strongly reduced. Few important aspects of the cytotoxic effects of nanoparticles were discussed on standard J774.E murine macrophages and U2OS human osteosarcoma cell lines as well.

\section{Experimental section}

\subsection{Apparatus}

$\mathrm{X}$-ray powder diffraction (XRD) measurements were performed using X'Pert PRO X-ray diffractometer (Cu, Ka1: $1.54060 \AA)$ (PANalytical). Transmission electron microscopy (TEM) and selective area electron diffraction were carried out using Philips CM-20 Super Twin microscope, operated at $200 \mathrm{kV}$. Preparation of the samples involved deposition of ethanol/water nanoparticle colloid droplet on the carbon covered copper microscope grid and drying under IR lamp. Mean particle size determination was performed using volume-weighted equation:

$$
d_{\mathrm{av}}=\sum \frac{n_{\mathrm{i}} d_{\mathrm{i}}^{4}}{n_{\mathrm{i}} d_{\mathrm{i}}^{3}},
$$

where $d_{\mathrm{av}}$ stays for mean primary size of particles, $n_{\mathrm{i}}$ is the number of particles of given size and $d_{\mathrm{i}}$ is diameter of $\mathrm{i}$ particle. Elemental analysis was carried out using a scanning electron microscope FEI Nova NanoSEM 230 equipped with EDS spectrometer (EDAX PegasusXM4), for reliable statistics 10 readings from different areas of each sample were carried out. Hydrodynamic size was measured using dynamic light scattering technique (DLS) by means of Malvern Zetasizer Nano-ZS instrument operating under He-Ne $633 \mathrm{~nm}$ laser and equipped with the Dispersion Technology Software for data collection and analysis, as well as additionally verified using Nanosight NS 500 automated station equipped with $405 \mathrm{~nm}$ line of laser diode as a light source backscattered further on measured objects. The particle/object size analysis was done using Nanosight NTA 2.3 software. The $\mathrm{Mn}_{1-x} \mathrm{Ni}_{x} \mathrm{Fe}_{2} \mathrm{O}_{4}$ nanoparticles were dispersed at a concentration of $10 \mu \mathrm{g} \mathrm{ml}^{-1}$ in ultrapure water containing
$0.05 \%$ BSA for stabilization. Dispersions were allowed to equilibrate to $37{ }^{\circ} \mathrm{C}$ before at least three measurements per sample were made. Dispersion stability studies and absorption spectra were performed using time dependent absorption spectra recorded on a Cary 5E UV-VIS-NIR spectrophotometer using standard absorption cuvette (optical path $1 \mathrm{~cm}$ ). Several nanoparticles dispersions were prepared using highly concentrated stock solutions containing $38 \mathrm{mg} \mathrm{ml}^{-1}$ of particles. The final measurements were performed on dispersions with nanoparticle concentration of $80 \mu \mathrm{g} \mathrm{ml}^{-1}$ (in the range of apparatus sensitivity). The time dependent absorption measurements were conducted over 6 hours, at predefined time points. Sample dispersion prior and during measurements were not additionally shaken. Light to heat conversion measurements were done using $808 \mathrm{~nm}$ laser diode with controllable power density and sample temperature was controlled using an A40M FlirSystem thermovision camera. Cytotoxicity assessment was carried out on murine macrophage (J774.E) and human osteosarcoma (U2OS) cell lines. The tests were based on the enzymatic reduction of the tetrazolium salt MTT. The images of interacting nanoparticles with cells were acquired using inverted light microscope (AxioObserverA1, Zeiss) equipped with Cannon PowerShot digital camera.

\subsection{Synthesis of $\mathbf{M n}_{1-x} \mathrm{Ni}_{x} \mathrm{Fe}_{2} \mathrm{O}_{4}$ nanoparticles}

The $\mathrm{Mn}_{1-x} \mathrm{Ni}_{x} \mathrm{Fe}_{2} \mathrm{O}_{4}$ nanoparticles were synthesized using well described in the literature non-hydrolytic approach with microwave stimulation as a driving force of the chemical reaction. ${ }^{12,27,30}$ The $x$ value represents molar content of $\mathrm{Ni}^{2+}$ substitution and was chosen to be $0.2,0.5$ as well as 0.8 , respectively. Described preparation procedure is based on example of the $0.5 \mathrm{~g}$ final product fabrication with use of following substrates: $\mathrm{Mn}(\mathrm{acac})_{2}$ (99\%, Alfa Aesar), Ni(acac) $)_{2}(99 \%$, Alfa Aesar), as well as $\mathrm{Fe}(\mathrm{acac})_{3}(99 \%$, Alfa Aesar). Acac abbreviation refers to the acetylacetonate ligand. Therefore, for preparation of the nanoparticles with given composition $\mathrm{Mn}_{0.5} \mathrm{Ni}_{0.5} \mathrm{Fe}_{2} \mathrm{O}_{4} 0.28638 \mathrm{~g}$ $\mathrm{Mn}(\mathrm{acac})_{2}, 0.2906 \mathrm{~g}$ of $\mathrm{Ni}(\mathrm{acac})_{2}$, and $1.56515 \mathrm{~g} \mathrm{Fe}(\mathrm{acac})_{3}$, were taken respectively. Metal complexes were transferred to $70 \mathrm{ml}$ of acetophenone (99\%, Sigma Aldrich, without further purification) immediately forming an intense red solution and subsequently moved to the PTFE (polytetrafluoroethylene) container which was placed in the Ertec ${ }^{\circledR}$ Magnum V2 microwave reactor. The total reaction time was $90 \mathrm{~min}$ at $250{ }^{\circ} \mathrm{C}$ and $35 \mathrm{~atm}$. As a product, dark brown suspension containing nanoparticles was obtained. The $\mathrm{Mn}_{0.5} \mathrm{Ni}_{0.5} \mathrm{Fe}_{2} \mathrm{O}_{4}$ was washed with ethanol (96\%, Avantor Performance Materials) using laboratory centrifuge (10 $000 \mathrm{rpm}, 10 \mathrm{~min}$ ) until the characteristic acetophenone odour was no longer detectable (usually no less than six times). After removing the mother solution nanoparticles were transferred to ethanol-water mixture $(90: 10)$. The batch was divided in two pieces, one part was dried in laboratory drier for XRD, TEM, and SEM-EDS analysis, second part of the colloid was used to perform dispersion stability and cytotoxicity assessments as well as heat energy conversion measurements. Description of the nanoparticle suspensions treatment for biological tests was described in detail, in referring paragraph. 
2.3. Cytotoxicity assessment of $\mathrm{Mn}_{x} \mathrm{Ni}_{1-x} \mathrm{Fe}_{2} \mathrm{O}_{4}$ nanoparticles in J774.E murine macrophages and U2OS human osteosarcoma cell line - materials and methods

Cytotoxicity assessment was carried out on murine macrophage (J774.E) and human osteosarcoma (U2OS) cell lines. Both cell lines were obtained from certified providers: U2OS line was obtained from ATCC (Manassas, Va, USA) and J774.E line was obtained from the Institute of Immunology and Experimental Therapy, Polish Academy of Sciences (Wrocław, Poland). The choice of the in vitro model was based on the fact that under in vivo conditions, macrophages form the primary line of response to particulate matter. Thus, they are responsible for the distribution and clearance of nanoparticles and their agglomerates. On the other hand, U2OS is a line derived from human case of osteosarcoma. This type of cancer belongs to one of the most aggressive neoplastic diseases and, apart from surgical treatment, often requires systemic chemotherapy and irradiation. Due to this feature, it seems to be a proper model for testing novel theranostic approaches for systemic use. Cells were cultured in RPMI-1640 medium (Institute of Immunology and Experimental Therapy, Wrocław, Poland) supplemented with $10 \%$ fetal bovine serum (FBS, Sigma, USA), Lglutamine (Sigma, UK) and antibiotics (penicillin and streptomycin, Sigma, Germany). For the cytotoxicity assessment, cells were seeded in 96-well-plates (NUNC, Denmark) at a density of 10 $\times 10^{3}$ (J774.E) or $3 \times 10^{3}$ (U2OS) cells per well and pre-incubated at $37{ }^{\circ} \mathrm{C}$ for $24 \mathrm{~h}$ in a humidified atmosphere of $5 \% \mathrm{CO}_{2}$. After that, nanoparticle dispersions were added. Highly stabile concentrated stock dispersions of nanoparticles were prepared and further diluted in ethanol. Dispersions in complete culture medium were prepared by adding an appropriate volume of a given dilution to provide constant (non-cytotoxic) exposure to the diluent. Cells were exposed to the nanoparticle dispersions for $24 \mathrm{~h}\left(5 \% \mathrm{CO}_{2}, 37^{\circ} \mathrm{C}\right)$. Control cells were exposed to the supernatant of the highest particle concentration subjected to ultracentrifugation for $3 \mathrm{~h}$. This step was undertaken to exclude possible toxic effects of potential soluble compound e.g. released ions, contaminants. No such effect was observed. After $24 \mathrm{~h}$, the MTT assay was carried out. The test is based on the enzymatic reduction of the tetrazolium salt MTT [3(4,5-dimethylthiazol-2-yl)-2,5-diphenyl-tetrazoliumbromide] in living, metabolically active cells. Preliminary experiment showed no interference of nanoparticles with either MTT or formazan in a cell-free system. After $2 \mathrm{~h}$ of incubation, cells were lysed and left for complete dissolution of purple-colored metabolite. After $24 \mathrm{~h}$, the optical density (OD) was measured by means of a microplate reader (ELx800, BioTek, USA) at the wavelength of $570 \mathrm{~nm}$. The OD of control cells was taken as $100 \%$. The results were obtained from at least 3 independent experiments.

\section{Results and discussion}

\subsection{Structure, morphology and $\mathrm{Mn}_{1-x} \mathrm{Ni}_{x} \mathrm{Fe}_{2} \mathrm{O}_{4}$ nanoparticles dispersion stability}

Based on the XRD results (Fig. 1), one can note that the crystal structure of all samples corresponds well with the reference standard describing the $\mathrm{MnFe}_{2} \mathrm{O}_{4}$ cubic $F d \overline{3} m$ crystallographic system (ICSD card no. 24497). Moreover continues shift of the [3 11 1] plane towards higher $2 \Theta$ angles was observed as an effect of the cell parameters change induced by the substitution of the bigger $\mathrm{Mn}^{2+}$ (0.66 ̊ at C.N. 4) cation by smaller one $\mathrm{Ni}^{2+}(0.55 \AA)$, respectively. ${ }^{31}$

SEM-EDS elemental analysis (Fig. 2) confirmed a desired chemical composition of all nanoparticles within tested $\mathrm{Ni}^{2+}$ concentration range. This approach can be further easily adopted for the synthesis of other ferrites with great flexibility in chemical compositions ${ }^{12,27,30,32}$ as well as extended for different types of mixed metal oxides. ${ }^{33-36}$ Representative TEM image (Fig. 3) gave a direct confirmation of the presence of small and spherical nanoparticles with primary size of $6 \mathrm{~nm} \pm 4 \mathrm{~nm}$ (primary particle size refers to the size related to dry powders) with relatively low agglomeration degree. SAED picture shows typical electron diffraction image characteristic for ferrite family providing additional confirmation of structural purity.

DLS technique (both instruments Zetasizer and NS 500) was utilized to give a quick answer on the non-modified nanoparticle state in the water dispersion since the main focus was placed on application of such objects in the heat energy transfer bio-applications. Both instruments shown the same results implying that, independent of the chemical composition, the hydrodynamic size was around $90 \mathrm{~nm}$ in all cases with low polydispersity index (PDI). The main difference between particle size estimated from TEM and DLS can be related directly to the action of water promoting agglomeration process as well as so-called formation of particle clusters (magnetic clustering) since fabricated nanoparticles were not treated with any special surface modifying agents (surfactants).

The time dependent absorption spectra were performed in order to test the effect of additives (water, RPMI buffer, cell medium, phosphocreatine (PCr), adenosine-tri-phosphate (ATP) as well as bovine serum albumin (BSA)) on the stability of nanoparticle dispersions. We assumed that at time zero, the absorbance of nanoparticles in water dispersions at $390 \mathrm{~nm}$ has a maximum value $(100 \%)$. Therefore, the measurements were conducted over 6 hours, at predefined time points. Timedependent changes in absorbance were directly related to the amount of absorbers remaining in the dispersion. Afterwards the stability curves were re-constructed (Fig. 4). One can note that BSA together with PCr provided the best conditions for particle stabilization, almost the same effect was observed for the cell medium (no surprise since it contains relevant proteins) whereas RPMI buffer and ATP both had detrimental effect on nanoparticle stability. Both RPMI and ATP, due to their destabilizing effect on nanoparticles, can be used also for particle separation from the solution if necessary. This simple technique can be extremely helpful in fast estimation of the possible stabilizing/destabilizing behavior of different substances, electrolytes and etc. What is worth mentioning is that the nanoparticles dispersed only in water shown rather good stability over studied period of time.

\subsection{In vitro assessment of $\mathrm{Mn}_{1-x} \mathrm{Ni}_{x} \mathrm{Fe}_{2} \mathrm{O}_{4}$ nanoparticles cytotoxicity to J774.E murine macrophages and U2OS human osteosarcoma cells}

Since in the scientific literature controversies exist regarding the use of colorimetric assays for nanoparticle cytotoxicity 


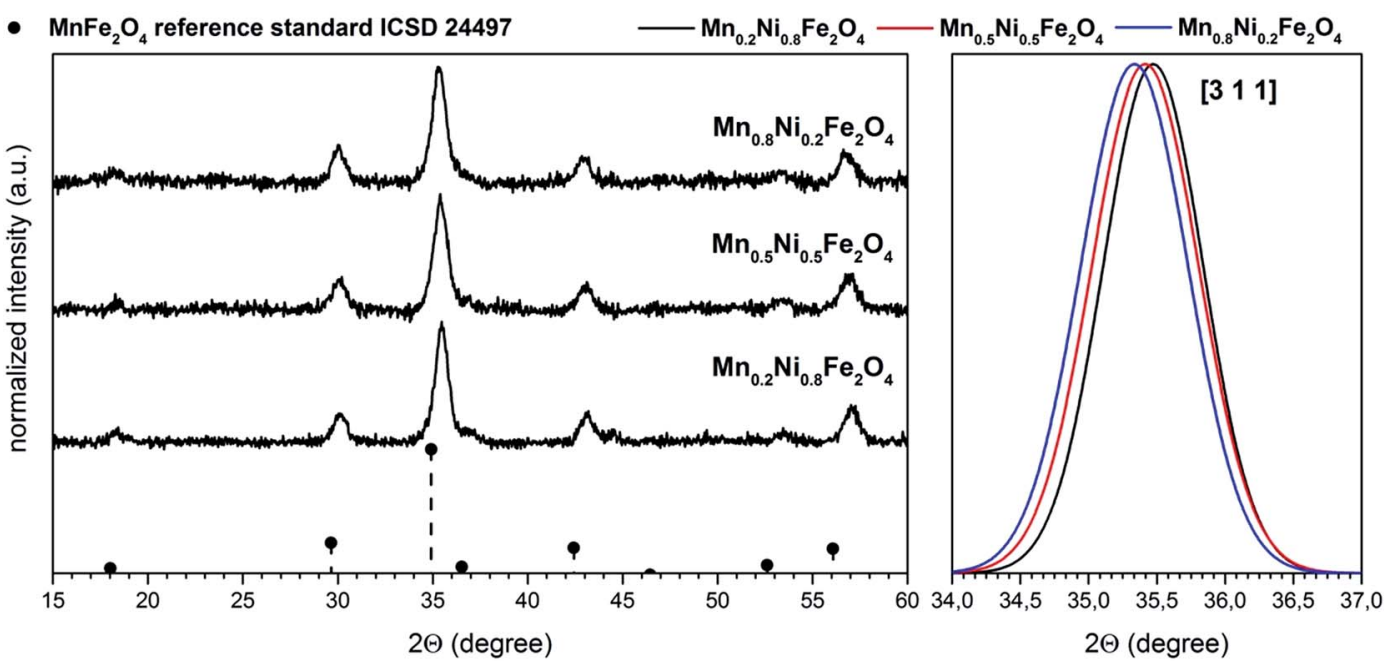

Fig. 1 XRD patterns of the $\mathrm{Mn}_{1-x} \mathrm{Ni}_{x} \mathrm{Fe}_{2} \mathrm{O}_{4}$ nanoparticles together with $\left(\begin{array}{lll}3 & 1 & 1\end{array}\right)$ plane shift induced by $\mathrm{Ni}^{2+}$ doping.

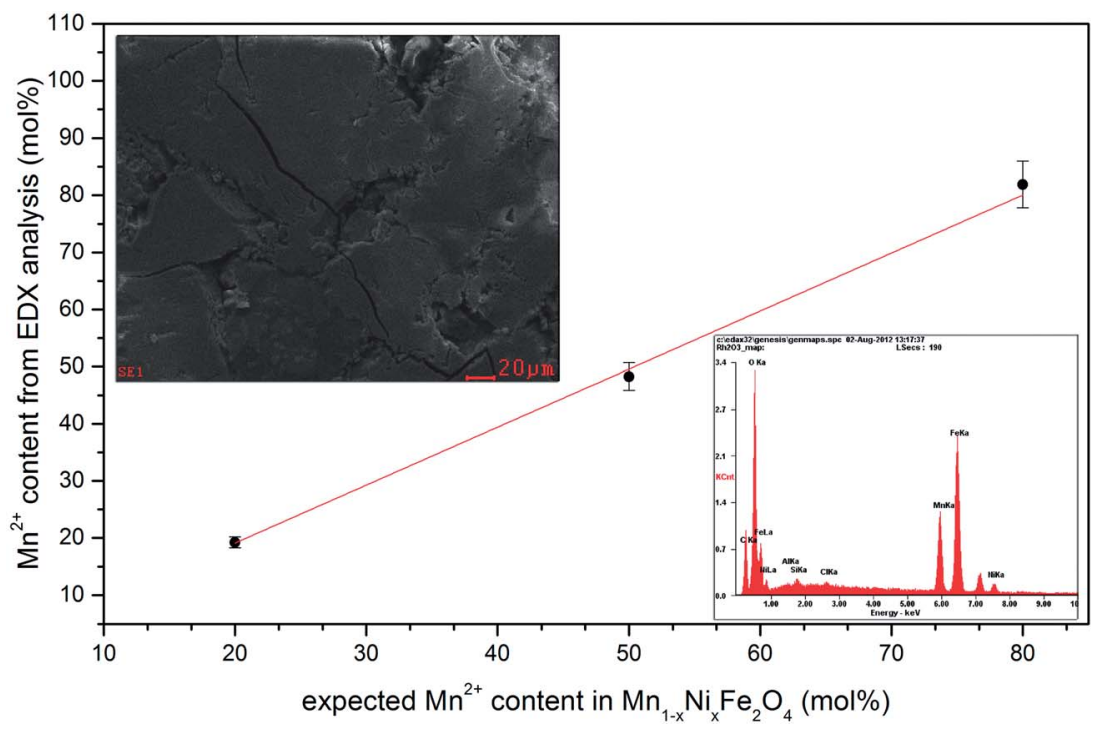

Fig. 2 SEM-EDS analysis of the $\mathrm{Mn}_{1-x} \mathrm{Ni}_{x} \mathrm{Fe}_{2} \mathrm{O}_{4}$ nanoparticles.

studies, in our previous papers we have described the use of trypan blue exclusion assay (TBEA) as a non-colorimetric method to determine particle toxicity. Although useful, this method is rather labor-intensive and problematic with higher number of different materials to assess. The major problem with the use of colorimetric assays (like MTT) in nanoparticle cytotoxicity assessment is the intensive color of many such materials (including ferrites) at higher concentrations and possible interactions with the dyes. Thus, in this studies the maximum concentration applied $\left(10 \mu \mathrm{g} \mathrm{ml}^{-1}\right)$ was chosen based on the lack of interaction with the MTT assay and inhibitory concentrations known from studies on related materials. ${ }^{12}$ Comparison of particle cytotoxicity in two cell lines is visualized in Fig. 5.

In case of macrophages, an interesting tendency was observed. The lower the concentration of manganese in the particle, the higher the cytotoxicity of the material. This can be seen in the values of the particle concentration that decreases cell viability by $50 \%\left(\mathrm{IC}_{50}\right)$. For J774.E cells, the $\mathrm{IC}_{50}$ values are 4.33; 6.95 and $>10 \mu \mathrm{g} \mathrm{ml}{ }^{-1}$ for $\mathrm{Mn}_{0.2} \mathrm{Ni}_{0.8} \mathrm{Fe}_{2} \mathrm{O}_{4} ; \mathrm{Mn}_{0.5} \mathrm{Ni}_{0.5} \mathrm{Fe}_{2} \mathrm{O}_{4}$ and $\mathrm{Mn}_{0.8} \mathrm{Ni}_{0.2} \mathrm{Fe}_{2} \mathrm{O}_{4}$, respectively. Surprisingly, this effect was not seen in U2OS cells where the curve of inhibition looks more uniform. The $\mathrm{IC}_{50}$ values for these cells are 9.57; 6.94 and 4.06 $\mu \mathrm{g} \mathrm{ml}{ }^{-1}$ for $\mathrm{Mn}_{0.2} \mathrm{Ni}_{0.8} \mathrm{Fe}_{2} \mathrm{O}_{4} ; \mathrm{Mn}_{0.5} \mathrm{Ni}_{0.5} \mathrm{Fe}_{2} \mathrm{O}_{4}$ and $\mathrm{Mn}_{0.8} \mathrm{Ni}_{0.2^{-}}$ $\mathrm{Fe}_{2} \mathrm{O}_{4}$, respectively. In general, both cell types seem to exhibit detrimental effects when exposed to the studied nanoparticles. In our previous study on $\mathrm{Co}_{1-x} \mathrm{Mn}_{x} \mathrm{Fe}_{2} \mathrm{O}_{4}$ ferrite nanoparticle cytotoxicity in the same set of cell lines a more differentiated response was observed. ${ }^{12}$

While macrophages have shown concentration-dependent loss of viability, osteosarcoma cells seemed not to be lethally affected. The difference between these studies may be 
a)

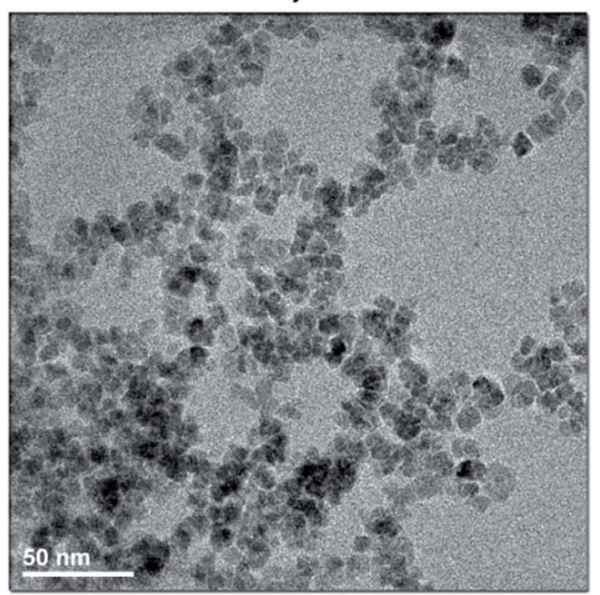

c)

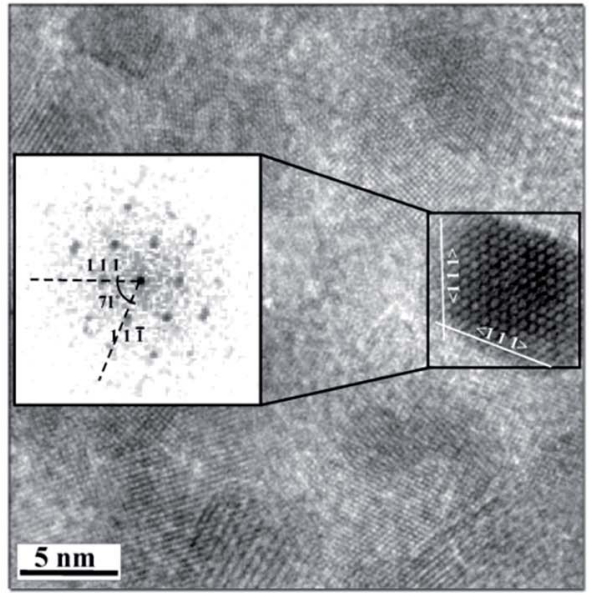

b)

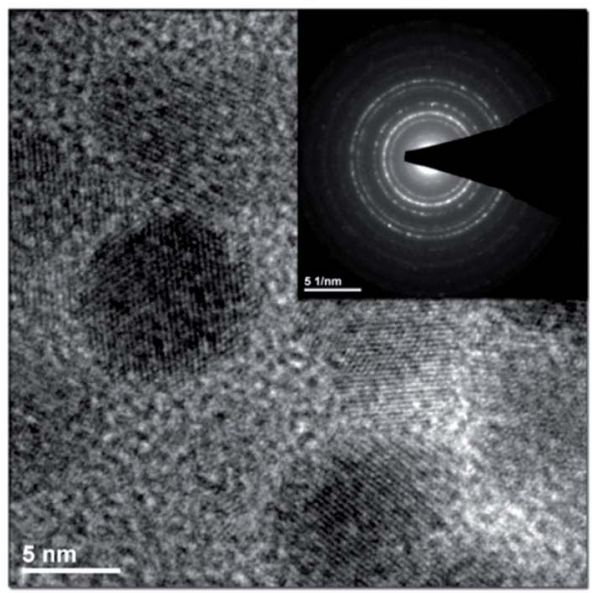

d)

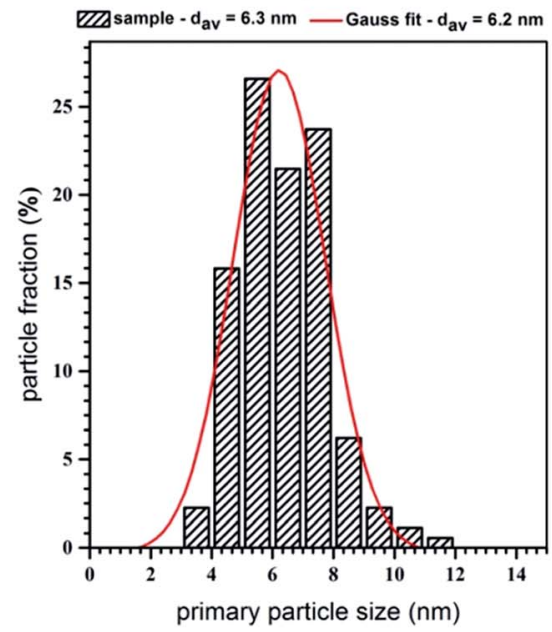

Fig. 3 Representative TEM and SAED images of the $\mathrm{Mn}_{0.8} \mathrm{Ni}_{0.2} \mathrm{Fe}_{2} \mathrm{O}_{4}$ nanoparticles and its particle size distribution.

- water - RPMI buffer $\Delta$ cell medium $\nabla \mathrm{PCr} \otimes \mathrm{ATP} *$ BSA

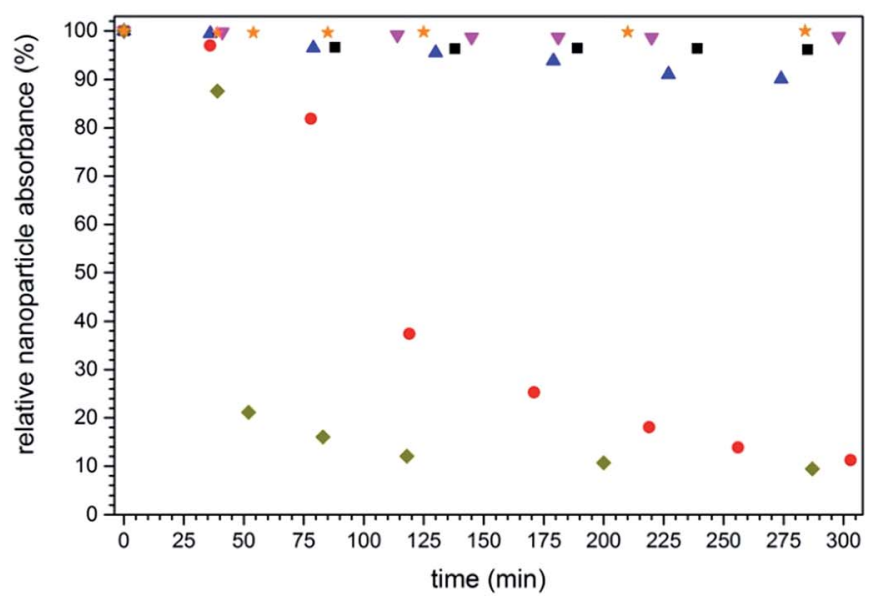

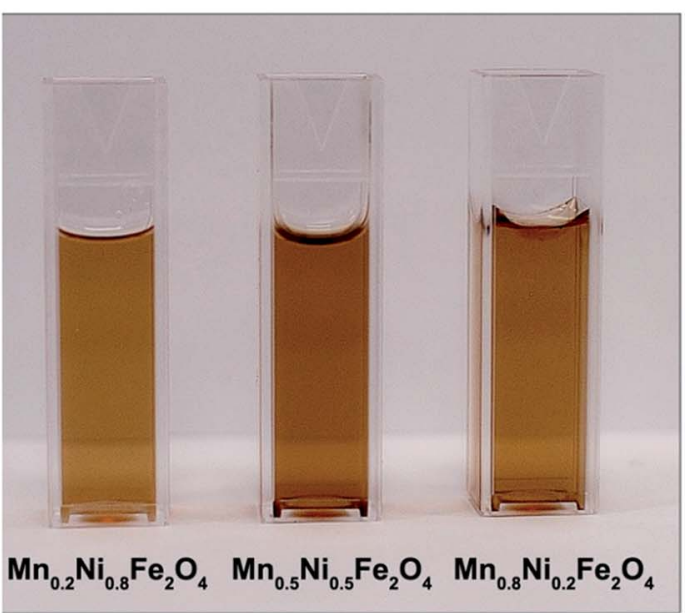

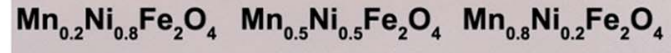

Fig. 4 Time dependence of nanoparticles dispersions absorbance effect of different stabilizing agents.

associated with the applied assay. Since TBEA measures the number of living cells and MTT test measures the metabolic activity of cells, the resulting two parameters may be different for the same exposure. In such case, MTT assay may allow for the detection of sub-lethal derangements in cell physiology producing lower $\mathrm{IC}_{50}$ values compared to TBEA. Similar to our 

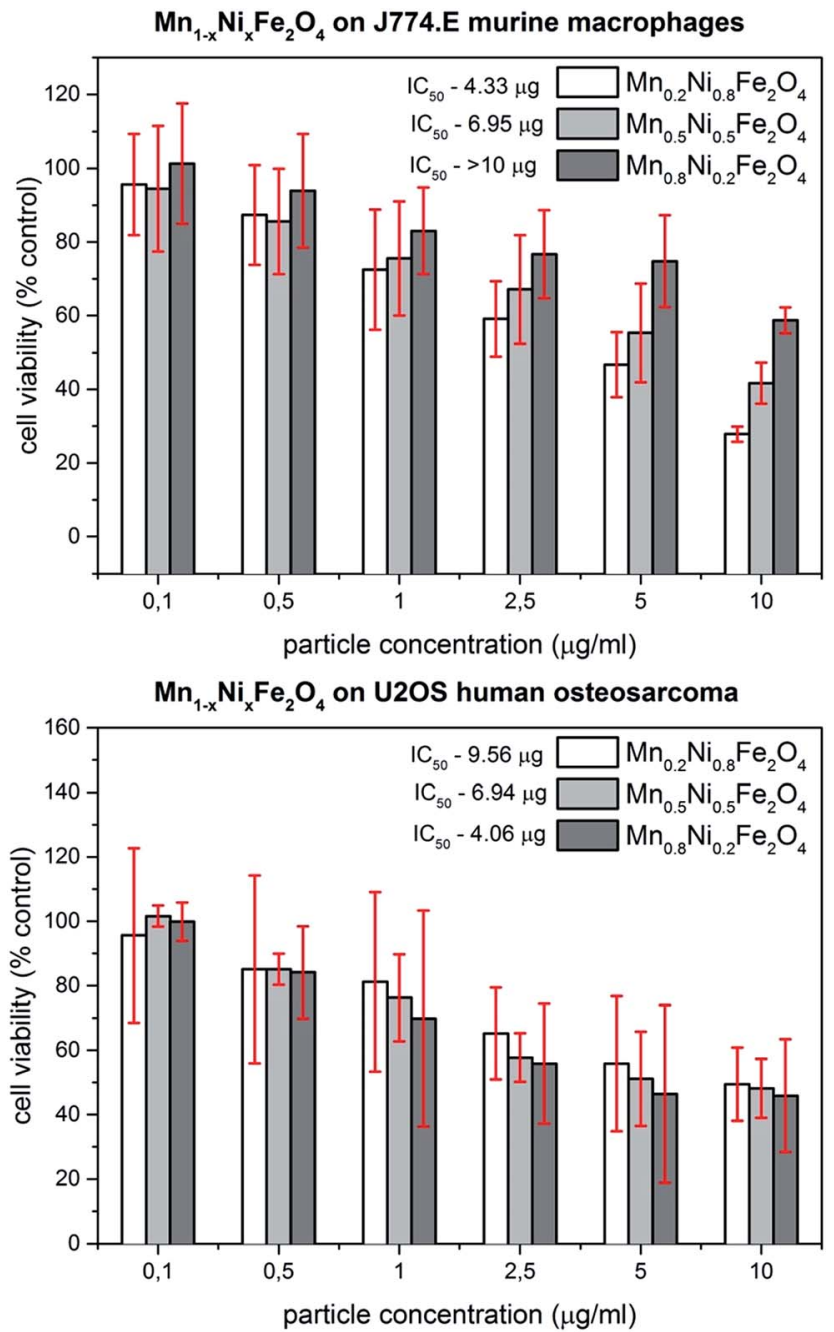

Fig. 5 Viability of J774.E and U2OS cell lines exposed to $\mathrm{Mn}_{0.2} \mathrm{Ni}_{0.8^{-}}$ $\mathrm{Fe}_{2} \mathrm{O}_{4} ; \mathrm{Mn}_{0.5} \mathrm{Ni}_{0.5} \mathrm{Fe}_{2} \mathrm{O}_{4}$ and $\mathrm{Mn}_{0.8} \mathrm{Ni}_{0.2} \mathrm{Fe}_{2} \mathrm{O}_{4}$ nanoparticles for $48 \mathrm{~h}$ as determined by MTT assay.

previous study, visual inspection of cells exposed to particle dispersions revealed high loading of macrophages and low to moderate loading of osteosarcoma cells (Fig. 6). This difference is related to phagocytic activity of macrophages and their natural role in elimination of particulate matter under in vivo conditions. Since the $\mathrm{Mn}_{0.8} \mathrm{Ni}_{0.2} \mathrm{Fe}_{2} \mathrm{O}_{4}$ nanoparticles shown the lowest cytotoxic effects this sample was chosen for further characterization of light to heat conversion.

\subsection{Conversion of NIR light to heat energy}

Light to heat conversion results on dispersions of nanoparticles containing different concentrations of magnetic material $(0.3$ up to $3 \mathrm{mg} \mathrm{ml}^{-1}$ ) were plotted in Fig. 7 as a function of laser power density and exposure time. For comparison, test of heat generation on dry powders was performed as well (see inset in Fig. 7). However, due to the extremely rapid heating of dried nanoparticles, it was impossible to measure temperature time dependence with the applied measuring system.
The maximum temperature achieved on dry powders in this study was $300{ }^{\circ} \mathrm{C}$ at laser power of $1.5 \mathrm{~W} \mathrm{~cm}^{-2}$. The heating capacity of the $\mathrm{Mn}_{1-x} \mathrm{Ni}_{x} \mathrm{Fe}_{2} \mathrm{O}_{4}$ was calculated by the specific absorption rate for the nanoparticle dispersions defined as follows:

$$
\mathrm{SAR}=C \frac{\mathrm{d} T}{\mathrm{~d} t},
$$

where $C$ is the specific heat capacity, $\mathrm{d} T$ is the differential temperature increase in time $\mathrm{d} t$. The heat capacity of dispersion was estimated by using equation:

$$
\begin{aligned}
C= & \left(W_{\text {nanoparticle }} C_{\text {nanoparticle }}+W_{\text {water }} C_{\text {water }}\right) / \\
& \left(W_{\text {nanoparticle }}+W_{\text {water }}\right),
\end{aligned}
$$

where $W_{\text {nanoparticle }}$ and $W_{\text {water }}$ are mass of nanoparticle and water and $C_{\text {nanoparticle }}$ and $C_{\text {water }}$ are specific heat capacities of nanoparticle $\left(0.87 \mathrm{~J} \mathrm{~g}^{-1}{ }^{\circ} \mathrm{C}^{-1}\right)$ and water $\left(4.186 \mathrm{~J} \mathrm{~g}^{-1}{ }^{\circ} \mathrm{C}^{-1}\right)$, respectively. ${ }^{4,37}$ Values of $\mathrm{d} T / \mathrm{d} t$ were calculated from data representing the heating behavior of nanoparticles for the very first $60 \mathrm{~s}$ of NIR light exposure. The minimum temperature limit for hyperthermia $\left(42^{\circ} \mathrm{C}\right)$ for all dispersion was achieved after $4 \mathrm{~min}$ of $808 \mathrm{~nm}$ light exposure starting directly from room temperature $\left(25{ }^{\circ} \mathrm{C}\right)$. As in the case of the non-substituted $\mathrm{MnFe}_{2} \mathrm{O}_{4}$ nanoparticles for hyperthermia but under action of AC magnetic field increase of concentration of particles leads to either increase or decrease of heating capacity (Table 1).

This depends on the type of dipolar interactions which are strongly related to the particle diameter, shape, surface coating thus synthetic route. ${ }^{29,38}$ The SAR values are proportional to the nanoparticle concentration in dispersions and increase almost linearly. It can be seen that the increase in nanoparticles concentration has resulted in faster heating. However, at a cost of worse light penetration through the sample which is being absorbed and further blocked by particles placed in the proximal portion of the dispersion. For the low concentration regimes, not exceeding $300 \mu \mathrm{g} \mathrm{ml} l^{-1}$, which is still high enough in terms of possible cytotoxicity, sample heating occurs within the whole volume almost evenly. Further studies on optimization of the beam size, shape etc. for more efficient light penetration and absorption as well as nanoparticles modification will be necessary to conduct in future.

Fig. 8 presents the absorption spectra of $\mathrm{Mn}_{0.8} \mathrm{Ni}_{0.2} \mathrm{Fe}_{2} \mathrm{O}_{4}$ nanoparticle dispersions as a function of their concentration. In the case of the most concentrated samples signal saturation was achieved upon exciting nanoparticles concentration above 250 $\mu \mathrm{g} \mathrm{ml} \mathrm{m}^{-1}$ (very strong absorption). Therefore such calculations make sense only for the less concentrated samples. In order to calculate the efficiency of the light to heat conversion at $808 \mathrm{~nm}$ well known formula was used:

$$
\Phi_{\mathrm{abs}}{ }^{808}=\sigma_{\mathrm{abs}}{ }^{808} / \sigma_{\mathrm{ext}}{ }^{808}
$$

where $\Phi_{\text {abs }}$ is the absorption efficiency, $\sigma_{\text {abs }}$ refers to absorption cross section and $\sigma_{\text {ext }}$ is extinction cross section, respectively. ${ }^{26}$ Since the nanoparticles are dark brown and they are not showing any fluorescence it can be assumed that all of the 

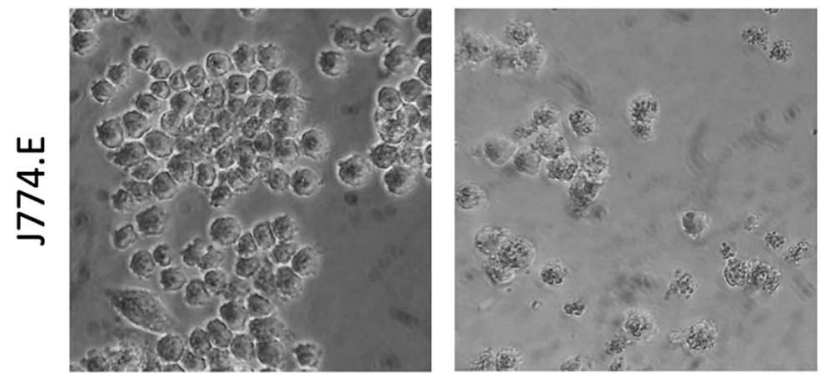

control

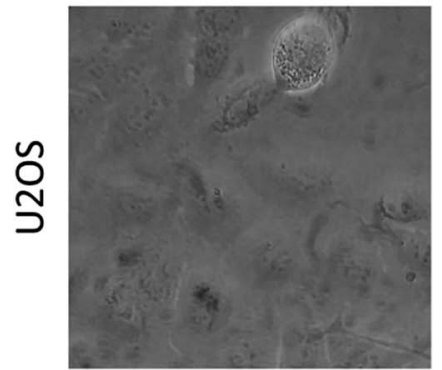

$\mathrm{Mn}_{0.2} \mathrm{Ni}_{0.8} \mathrm{Fe}_{2} \mathrm{O}_{4}$

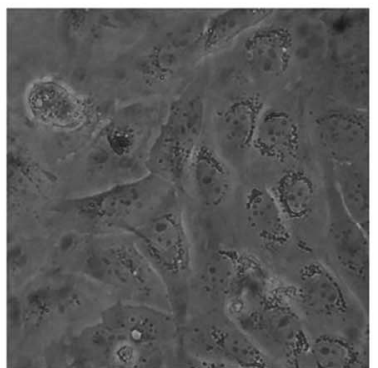

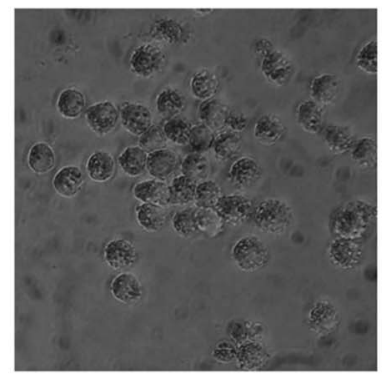

$\mathrm{Mn}_{0.5} \mathrm{Ni}_{0.5} \mathrm{Fe}_{2} \mathrm{O}_{4}$

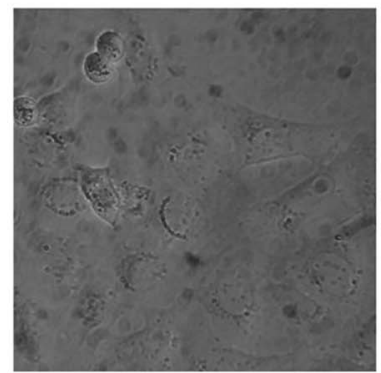

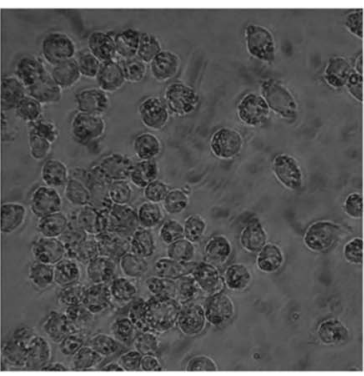

$\mathrm{Mn}_{0.8} \mathrm{Ni}_{0.2} \mathrm{Fe}_{2} \mathrm{O}_{4}$

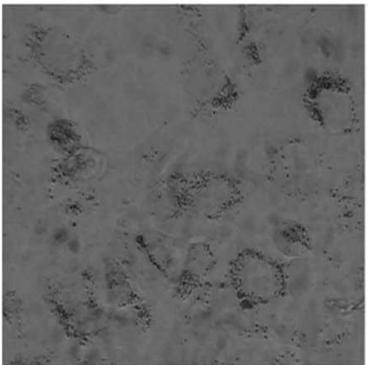

Fig. 6 Cell morphology in control (leftmost panels) and exposed cells of J774.E and U2OS cell lines (concentration of $10 \mu \mathrm{g} \mathrm{ml}{ }^{-1}$, magnification: $400 \times$ ). Brown granules of internalized agglomerates are particularly visible in J774.E macrophages.

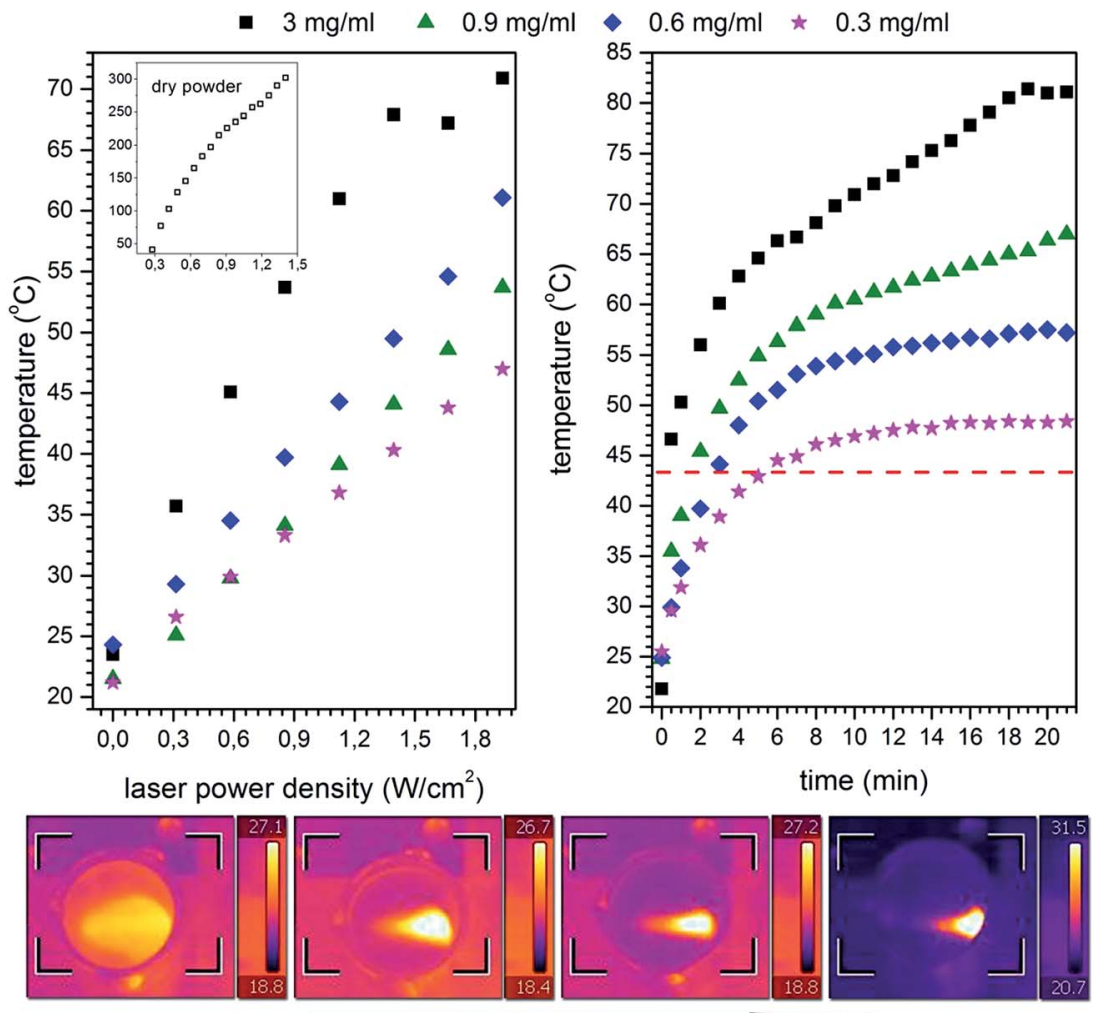

nanoparticle concentration increase

Fig. 7 Laser power dependence on nanoparticles dispersion temperature (left) as well as evolution of the sample temperature over time (right). Inset in left figure shows results achieved for dry powder. Bottom images show concentration effect on dispersion heating ability after $60 \mathrm{~s}$. 
Table 1 Specific absorption rate and $\mathrm{d} T / \mathrm{d} t$ value as a function of nanoparticle concentration in dispersion

\begin{tabular}{lcr}
\hline $\begin{array}{l}\text { Particle concentration } \\
\left.(\mathrm{mg} \mathrm{ml})^{-1}\right)\end{array}$ & $\begin{array}{l}\mathrm{d} T / \mathrm{d} t \\
\left({ }^{\circ} \mathrm{C} \mathrm{s}^{-1}\right)\end{array}$ & $\begin{array}{l}\text { SAR } \\
\left(\mathrm{W} \mathrm{g}^{-1}\right)\end{array}$ \\
\hline 3 & 28.5 & 119.35 \\
0.9 & 14.2 & 59.44 \\
0.6 & 8.9 & 37.25 \\
0.3 & 6.4 & 26.78
\end{tabular}

absorbed light will be converted into the heat energy exclusively. Value of the absorption cross section $\sigma_{\text {abs }}$ was estimated to be $3.24 \times 10^{-19} \mathrm{~cm}^{2}$ per molecule, whereas extinction cross section was calculated using following formula:

$$
\sigma_{\mathrm{ext}}{ }^{808}=\alpha_{\mathrm{ext}}{ }^{808} / c_{\mathrm{NPs}}
$$

where $\alpha_{\text {ext }}$ is the extinction coefficient (at $808 \mathrm{~nm}$ ) and $c_{\mathrm{NPs}}$ represents the nanoparticle concentration. As it can be seen the extinction cross section together with extinction coefficient of the nanoparticle dispersion are concentration dependent. In the case of studied magnetic material the calculated heating efficiency increase significantly with concentration of nanoparticle dispersions. However for higher concentrated samples it is not possible to estimate the heating efficiency by using 'optical method', therefore calculation of the SAR parameter seems to be more reasonable in such a case. Comparison of the heating efficiency of the $\mathrm{Mn}_{0.8} \mathrm{Ni}_{0.2} \mathrm{Fe}_{2} \mathrm{O}_{4}$ nanoparticles with the carbon nanotubes (CNTs) or gold nanoparticles (AuNPs) places this material in a slightly different compounds league. Much lower particle concentrations are necessary to achieve comparable values of heating efficiencies in the case of CNTs or AuNPs. ${ }^{25,26}$ However, magnetic materials, as it has been shown by Espinosa et al., ${ }^{21}$ can be successfully used in hyperthermia
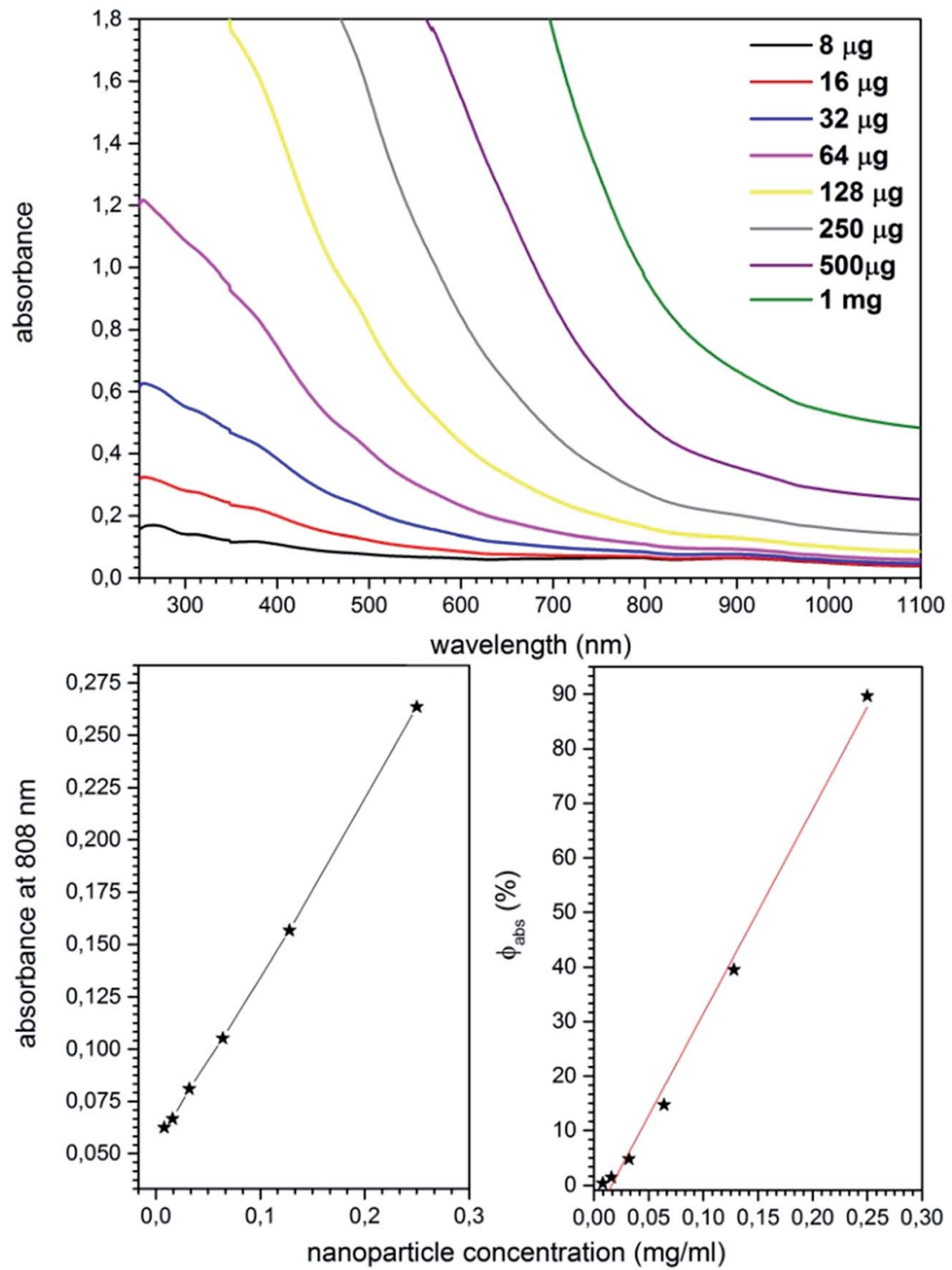

Fig. 8 Absorption spectra of $\mathrm{Mn}_{0.8} \mathrm{Ni}_{0.2} \mathrm{Fe}_{2} \mathrm{O}_{4}$ nanoparticle dispersion (upper), dispersion absorbance and conversion efficiency ( $\Phi_{\text {abs }}$ ) as a function of nanoparticle concentration (bottom). 
applications by taking advantage out of simultaneous stimulation of magnetic nanoparticles with both alternating magnetic field and NIR laser exposure.

\section{Conclusions}

$\mathrm{Mn}_{1-x} \mathrm{Ni}_{x} \mathrm{Fe}_{2} \mathrm{O}_{4}$ nanoparticles with primary particle size of $6 \mathrm{~nm}$ $\pm 4 \mathrm{~nm}$ were synthesized using fast and effective microwave stimulated technique without addition of surfactants or other specific agents to open more flexible post-surface modification potential. It was shown that the absorption measurements can be successfully used for studies of stabilizing/destabilizing effects of certain molecules on nanoparticles stability in water dispersions.

Both tested cell lines, J774.E murine macrophages and U2OS human osteosarcoma, exhibited dose-dependent cytotoxic effects upon interaction with the investigated nanoparticles. Comparison with previously studied ferrites $\mathrm{Co}_{1-x} \mathrm{Mn}_{x} \mathrm{Fe}_{2} \mathrm{O}_{4}$ has shown more differentiated cellular response with indication on lower cytotoxicity of $\mathrm{Mn}_{1-x} \mathrm{Ni}_{x} \mathrm{Fe}_{2} \mathrm{O}_{4}$ nanoparticles. Similar to our previous report, cells exposed to particle dispersions revealed high loading of macrophages and moderate loading of osteosarcoma cells. This difference was ascribed to phagocytic activity of macrophages and their natural role in elimination of particulate matter under in vivo conditions.

It was shown that the $\mathrm{Mn}_{1-x} \mathrm{Ni}_{x} \mathrm{Fe}_{2} \mathrm{O}_{4}$ nanoparticles dispersion shown effective light-to-heat conversion upon exposure of samples to NIR irradiation which can be potentially attractive in thermal based bio-related applications without use of external AC magnetic field. The calculated SAR was proportional to the nanoparticle concentration and increased linearly with particle concentration. Increase of nanoparticles amount leads to faster heating, but at a cost of worse light penetration through the sample. It was proven that the sufficient temperature for the thermal based therapies and temperature induced drug release can be achieved on $\mathrm{Mn}_{1-x} \mathrm{Ni}_{x} \mathrm{Fe}_{2} \mathrm{O}_{4}$ ferrite nanoparticles with use of the NIR radiation instead of the AC magnetic field quite effectively.

\section{Acknowledgements}

The authors would like to thank M.Sc. E. Bukowska for XRD measurements. Financial support of the National Science Centre in course of realization of the Project 'Smart nanoparticles for bio-imaging and drug delivery' no. UMO-2011/01/ D/ST5/05827 is gratefully acknowledged.

\section{References}

1 M. Arruebo, R. Fernández-pacheco, M. R. Ibarra and J. Santamaría, Nano Today, 2007, 2, 22-32.

2 P. Pallab, G. Jyotsnendu, S. Gopal, D. S. Haladhar, P. M. Kaushala, B. Jayesh, B. Rinti and B. Dhirendra, $J$. Biomed. Mater. Res., Part B, 2007, 81, 12-22.

3 T. B. Huff, L. Tong, Y. Zhao, M. N. Hansen, J.-X. Cheng and A. Wei, Nanomedicine, 2007, 2, 125-132.
4 D. H. Kim, D. E. Nikles and C. S. Brazel, Materials, 2010, 3, 4051-4065.

5 D. H. Kim, D. E. Nikles, D. T. Johnson and C. S. Brazel, J. Magn. Magn. Mater., 2008, 320, 2390-2396.

6 A. Faraz, M. Saqib, N. M. Ahmad, F. Rehman, A. Maqsood, M. Usman, A. Mumtaz and M. H. Hassan, J. Supercond. Novel Magn., 2012, 25, 1025-1033.

7 K. P. Chae, W. O. Choi, J. Lee, B. Kang and S. H. Choi, J. Magn., 2013, 18, 21-25.

8 E. R. Kumar, A. S. Kamzin and T. Prakash, J. Magn. Magn. Mater., 2015, 378, 389-396.

9 R. Kesavamoorthi and C. R. Raja, J. Supercond. Novel Magn., 2016, 29, 2729-2734.

10 S. K. Jesudoss, J. J. Vijaya, L. J. Kennedy, P. I. Rajan, H. A. AlLohedan, R. J. Ramalingam, K. Kaviyarasu and M. Bououdina, J. Photochem. Photobiol., B, 2016, 165, 121132.

11 C. Fernandes, C. Pereira, M. P. Fernandez-Garcia, A. M. Pereira, A. Guedes, R. Fernandez-Pacheco, A. Ibarra, M. R. Ibarra, J. P. Araujo and C. Freire, J. Mater. Chem. C, 2014, 2, 5818-5828.

12 E. Zachanowicz, A. Zięcina, P. A. Mikołajczyk, K. Rogacki, M. Małecka, K. Marycz, M. Marędziak, B. Poźniak, M. Nowakowska, M. Tikhomirov, J. Miller, R. J. Wiglusz and R. Pązik, Eur. J. Inorg. Chem., 2016, 2016, 5315-5323.

13 Z. Beji, A. Hanini, L. S. Smiri, J. Gavard, K. Kacem, F. Villain, J. M. Grenèche, F. Chau and S. Ammar, Chem. Mater., 2010, 22, 5420-5429.

14 Q. A. Pankhurst, J. Connolly, S. K. Jones and J. Dobson, J. Phys. D: Appl. Phys., 2003, 36, R167-R181.

15 D. Jaque and F. Vetrone, Nanoscale, 2012, 4, 4301-4326.

16 C.-H. Quek and K. W. Leong, Nanomaterials, 2012, 2, 92-112.

17 D. Jaque, L. Martínez Maestro, B. del Rosal, P. HaroGonzalez, A. Benayas, J. L. Plaza, E. Martín Rodríguez and J. García Solé, Nanoscale, 2014, 6, 9494-9530.

18 K.-T. Yong, I. Roy, M. T. Swihart and P. N. Prasad, J. Mater. Chem., 2009, 19, 4655-4672.

19 H. Chen, J. Burnett, F. Zhang, J. Zhang, H. Paholak and D. Sun, J. Mater. Chem. B, 2014, 2, 757-765.

20 M. Chu, Y. Shao, J. Peng, X. Dai, H. Li, Q. Wu and D. Shi, Biomaterials, 2013, 34, 4078-4088.

21 A. Espinosa, R. Di Corato, J. Kolosnjaj-Tabi, P. Flaud, T. Pellegrino and C. Wilhelm, ACS Nano, 2016, 10, 24362446.

22 S. Shen, S. Wang, R. Zheng, X. Zhu, X. Jiang, D. Fu and W. Yang, Biomaterials, 2015, 39, 67-74.

23 S. Shen, F. Kong, X. Guo, L. Wu, H. Shen, M. Xie, X. Wang, Y. Jin and Y. Ge, Nanoscale, 2013, 5, 8056-8066.

24 Z. Zhou, Y. Sun, J. Shen, J. Wei, C. Yu, B. Kong, W. Liu, H. Yang, S. Yang and W. Wang, Biomaterials, 2014, 35, 7470-7478.

25 L. M. Maestro, P. Haro-González, B. del Rosal, J. Ramiro, a J. Caamaño, E. Carrasco, A. Juarranz, F. Sanz-Rodríguez, J. G. Solé and D. Jaque, Nanoscale, 2013, 5, 7882-7889.

26 L. M. Maestro, P. Haro-González, A. Sánchez-Iglesias, L. M. Liz-Marzán, J. García Solé and D. Jaque, Langmuir, 2014, 30, 1650-1658. 
27 R. Pązik, E. Piasecka, M. Małecka, V. G. Kessler, B. Idzikowski, Z. Śniadecki and R. J. Wiglusz, RSC Adv., 2013, 3, 12230.

28 E. Mazarío, J. Sánchez-Marcos, N. Menéndez, M. Cañete, A. Mayoral, S. Rivera-Fernández, J. M. De La Fuente and P. Herrasti, J. Phys. Chem. C, 2015, 119, 6828-6834.

29 K. Vamvakidis, M. Katsikini, D. Sakellari, E. C. Paloura, O. Kalogirou and C. Dendrinou-Samara, Dalton Trans., 2014, 43, 12754-12765.

30 R. Pązik, A. Zięcina, E. Zachanowicz, M. Małecka, B. Poźniak, J. Miller, Z. Śniadecki, N. Pierunek, B. Idzikowski, L. Mrówczyńska, A. Ekner-Grzyb and R. J. Wiglusz, Eur. J. Inorg. Chem., 2015, 4750-4760.

31 R. D. Shannon, Acta Crystallogr., Sect. A: Cryst. Phys., Diffr., Theor. Gen. Crystallogr., 1976, 32, 751-767.

32 K. Wilkinson, B. Ekstrand-Hammarström, L. Ahlinder, K. Guldevall, R. Pazik, L. Kępiński, K. O. Kvashnina, S. M. Butorin, H. Brismar, B. Önfelt, L. Österlund,
G. a. Seisenbaeva and V. G. Kessler, Nanoscale, 2012, 4, 7383-7393.

33 R. Pazik, G. A. Seisenbaeva, S. Gohil, R. Wiglusz, L. Kępiński, W. Strek and V. G. Kessler, Inorg. Chem., 2010, 49, 26842691.

34 R. Pazik, G. A. Seisenbaeva, R. J. Wiglusz, L. Kepinski and V. G. Kessler, Inorg. Chem., 2011, 50, 2966-2974.

35 R. Pazik, R. Tekoriute, S. Håkansson, R. Wiglusz, W. Strek, G. a. Seisenbaeva, Y. K. Gun'ko and V. G. Kessler, Chem.Eur. J., 2009, 15, 6820-6826.

36 S. Abtmeyer, R. Païzik, R. J. Wiglusz, M. Małecka, G. a. Seisenbaeva and V. G. Kessler, Inorg. Chem., 2014, 53, 943-951.

37 I. Baker, Q. Zeng, W. Li and C. R. Sullivan, J. Appl. Phys., 2006, 99, 97-100.

38 N. D. Thorat, V. M. Khot, a B. Salunkhe, a I. Prasad, R. S. Ningthoujam and S. H. Pawar, J. Phys. D: Appl. Phys., 2013, 46, 105003. 